\title{
PENGARUH PENGGUNAAN MEDIA VIDEO REKAM LAYAR TERHADAP KEMAMPUAN BELAJAR PROPOSAL KELAS XI DI SMK NEGERI 2 WONOGIRI
}

\author{
FITRI ITUT RAHAYU \\ SMK Negeri 2 Wonogiri \\ e-mail: fififitro@gmail.com
}

\begin{abstract}
ABSTRAK
Pembelajaran Jarak Jauh di masa pandemi Covid-19 saat ini menimbulkan berbagai masalah, salah satunya adalah kurangnya pemahaman peserta didik terhadap materi pembelajaran. Karena terbatasnya akses tatap muka dengan pendidik dalam pelajaran bahasa Indonesia, tingkat pemahaman peserta didik kelas XI SMK Negeri 2 Wonogiri dalam materi proposal masih kurang. Pembelajaran bahasa Indonesia dalam bab proposal adalah bab yang cukup sulit sehingga butuh penjelasan yang cukup agar peserta didik lebih memahami detail pembelajaran. Pemahaman peserta didik terhadap proposal sangat minim sehingga menyulitkan peserta didik dalam memahami dan mempelajari proposal. Salah satu fokus permasalahan yang melatarbelakangi hal tersebut adalah kurang variatifnya media pembelajaran bahasa Indonesia dalam pelaksanaan Pembelajaran Jarak Jauh di masa pandemi. Untuk itu diperlukan terobosan baru dalam penggunaan media yang lebih inovatif dan efektif disesuaikan dengan model pembelajaran jarak jauh mata pelajaran bahasa Indonesia. Media yang digunakan adalah media video rekam layar. Tujuan dari penelitian ini adalah untuk mendeskripsikan pengaruh penggunaan media video rekam layar terhadap kemampuan belajar proposal peserta didik kelas XI SMK Negeri 2 Wonogiri serta mendeskripsikan besarnya pengaruh penggunaan media video rekam layar terhadap kemampuan belajar poposal peserta didik kelas XI SMK Negeri 2 Wonogiri. Metode yang digunakan dalam penelitian ini adalah jenis eksperimen semu dengan tipe Nonequivalent Control Group Design. Pengumpulan data yang digunakan peneliti adalah tes, observasi, dan dokumentasi. Simpulan penelitian ini adalah bahwa penggunaan media video rekam layar dalam pembelajaran jarak jauh ini memberikan pengaruh positif terhadap kemampuan belajar proposal.
\end{abstract}

Kata Kunci: pandemi Covid-19, media video rekam layar, proposal.

ABSTRACT
Distance Learning during the current Covid-19 pandemic causes various problems, one of which is the lack of understanding of students towards learning materials. Due to the limited access to face-to-face with educators in Indonesian language lessons, the level of understanding of $11^{\text {th }}$ grade students of SMKN 2 Wonogiri in the 2020-2021 school year class in the proposal material is still lacking. Learning Indonesian in the proposal chapter is a fairly difficult chapter so it requires sufficient explanation so that students better understand the details of learning. Students' understanding of the proposal is minimal, making it difficult for students to understand and study the proposal. One of the focus problems behind this is the lack of variety of Indonesian language learning media in the implementation of Distance Learning during the pandemic. For this reason, a new breakthrough is needed in the use of more innovative and effective media adapted to the distance learning model of Indonesian language subjects. The media used is screen recording video media. The purpose of this study was to describe the effect of using screen recording video media on the ability to study proposals for $11^{\text {th }}$ grade students of SMKN 2 Wonogiri in the 2020-2021 school year class and to describe the magnitude of the effect of using screen recording video media on popular learning abilities. $11^{\text {th }}$ grade students of SMKN 2 Wonogiri in the 2020-2021 school year class. The method used in this study is a quasi-experimental type with the Nonequivalent Control Group Design type. The data collection used by the researcher is tests, observations, and documentation. The conclusion of this study is that the use of screen recording video media in distance learning has a positive influence on the ability to study proposals. 
Keywords: pandemic Covid-19, screen recording video media, proposal.

\section{PENDAHULUAN}

Salah satu mata pelajaran yang diberikan sejak Sekolah Dasar adalah bahasa Indonesia. Pelajaran tersebut diberikan kepada peserta didik sampai dengan jenjang SMA/ SMK, bahkan perguruan tinggi. Komunikasi efektif peserta didik merupakan target keberhasilan pembelajaran bahasa. Keberhasilan tersebut ditentukan oleh banyak faktor, dan yang terpenting adalah faktor pengajar. Pengajar memiliki peran lebih erat kaitannya dengan keberhasilan pembelajar. Hal ini terutama berkenaan dengan kemampuan pengajar dalam menggunakan strategi pembelajaran Gilstrap dan Martin (dalam Budiningsih, 2005:50). Artinya, pengajar hendaknya selalu berupaya menerapkan strategi terbaik dalam pembelajaran dengan peserta didik, baik dari segi metode, media, maupun hal lain terkait dengan proses pembelajaran.

Slavin menyatakan bahwa belajar merupakan akibat dari interaksi stimulus dan respons. (2000:143). Pernyataan tersebut dapat diterjemahkan bahwa stimulus yang diberikan guru sangat penting agar menghasilkan respons peserta didik yang sesuai dengan konteks pembelajaran. Pentingnya kebermaknaan dalam pembelajaran berdasarkan konteks menuntut guru untuk memiliki berbagai keterampilan menyajikan bahan pembelajaran secara komunikatif. Stimulus dapat berupa bahan ajar yang disajikan oleh media pembelajaran. Bahan ajar dapat berupa materi, masalah, atau bahkan deretan pertanyaan terkait materi pembelajaran. Sedangkan media pembelajaran dapat berupa media audio, visual, ataupun kombinasinya.

Dari pengalaman peneliti, dalam pembelajaran tatap muka tahun yang lalu, materi proposal dirasa sulit bagi peserta didik. Ini jelas terlihat pada nilai yang tidak setinggi pada materi lain. Dibutuhkan perlakuan khusus saat pembelajaran materi proposal agar peserta didik lebih optimal dalam belajar proposal. Dibutuhkan berbagai inovasi dan kreasi pendidik serta motivasi peserta didik.

Dalam PJJ (Pembelajaran Jarak Jauh) dipastikan akan lebih sulit lagi. Pembelajaran Jarak Jauh di masa pandemi Covid-19 ini menimbulkan berbagai masalah, salah satunya adalah kurangnya pemahaman peserta didik terhadap materi karena terbatasnya akses tatap muka dengan pendidik Dalam pelajaran bahasa Indonesia, tingkat pemahaman peserta didik kelas XI SMK Negeri 2 Wonogiri dalam materi proposal masih kurang. Pembelajaran bahasa Indonesia dalam bab proposal adalah bab yang cukup sulit sehingga butuh penjelasan yang cukup agar peserta didik lebih memahami detail pembelajaran. Pemahaman peserta didik terhadap proposal sangat minim, bahkan menghadirkan nilai yang kurang memadai bagi peserta didik terlebih pada masa pandemi ini. Data nilai peserta didik pada dua tahun pelajaran terakhir dalam materi pokok proposal memaparkan bahwa persentase nilai yang berada pada interval di bawah KKM mendominasi kelas pada dua tahun pelajaran terakhir. Nilai terendah pada tahun pelajaran 2019/ 2020 adalah 10, dan secara mayor ada pada kisaran di bawah angka 70. Sedangkan pada tahun berikutnya 19 adalah nilai terendah dengan jumlah 3 peserta didik. Dalam tahun tersebut nilai mayor ada pada kisaran 41-50. Data tersebut menjelaskan bahwa materi proposal adalah materi yang sulit untuk dipahami. Proposal dalam materi kelas XI tidak hanya terbatas pada proposal kegiatan secara umum, namun juga pada kegiatan ilmiah, yaitu penelitian. Sejauh ini, penelitian adalah hal yang masih baru bagi peserta didik kelas XI sehingga menghadirkan kesulitan.

Media yang kurang variatif pada kenyataannya tidak membuat peserta didik semakin memahami materi. Selain karena motivasi yang kurang saat menggunakan media, peserta didik juga kurang optimal dalam mendapatkan informasi materi pembelajaran, terutama dalam mata pelajaran bahasa Indonesia. Untuk itu diperlukan terobosan baru dalam penggunaan media yang lebih variatif dan efektif disesuaikan dengan model pembelajaran jarak jauh mata pelajaran bahasa Indonesia, baik dalam pembelajaran jarak jauh secara langsung (misal dengan meeting virtual ataupun secara tidak langsung). Pemahaman peserta didik yang belum optimal tentunya menjadi permasalahan penting dalam mencapai kompetensi dasar yang ditetapkan dalam pembelajaran proposal sehingga perlu dicarikan solusi terbaik.

Dari latar belakang masalah di atas, peneliti tertarik untuk melakukan penelitian dengan 
judul "Pengaruh Penggunaan Media Video Rekam Layar terhadap Kemampuan Belajar Proposal Peserta Didik Kelas XI SMK Negeri 2 Wonogiri.

\section{METODE PENELITIAN}

Penelitian yang digunakan adalah jenis eksperimen semu dengan tipe Nonequivalent Control Group Design. Kelompok eksperimen maupun kelompok kontrol sama-sama diberi pre-test kemudian dicari hasilnya. Selanjutnya, kelompok eksperimen mendapatkan perlakuan yaitu penggunaan media video rekam layar dalam pembelajaran proposal, sedangkan kelompok kontrol tidak. Tahap selanjutnya, keduanya mendapatkan post-test untuk mengetahui hasil perlakuan yang telah diberikan. Secara ringkas, tahapan pelaksanaan penelitian ini adalah dari tahap praeksperimen, yaitu sebelum melakukan perlakuan (eksperimen), kedua kelas (kelompok eksperimen dan kelompok kontrol) diberikan pre-test atau tes awal, dengan maksud untuk mengetahui keadaan kedua kelas tersebut sebelum diberikan perlakuan. Bila tes awal menghasilkan perbedaan yang tidak berbeda jauh untuk kedua kelas ini, akan dilanjutkan ke tahap berikutnya, yaitu pemberian perlakuan (eksperimen).Kemudian dilanjutkan pada tahap perlakuan (treatment) pada kelas eksperimen sesuai dengan perlakuan yang telah direncanakan sebelumnya, sedangkan untuk kelas kontrol tidak diberikan perlakuan.

Penelitian diakhiri dengan tahap pascaeksperimen dengan mengadakan tes akhir. Tes ini dilakukan untuk mengetahui seberapa besar pengaruh pemberian perlakuan (treatment)penggunaan media video rekam layar pada pembelajaran proposal di kelas XI SMK Negeri 2 Wonogiri (kelas eksperimen). Tes akhir diikuti kelas eksperimen dan kontrol. Hasil tes ini akan dibandingkan dengan hasil tes awal.

Instrumen yang digunakan dalam penelitian ini adalah soal tes, observasi, dan dokumentasi. Penelitian ini menggunakan validitas isi (content validity) di mana isi instrumen akan dibandingkan dengan materi pelajaran. Penelitian ini menggunakan indeks validitas atau korelasi poin biserial (Point Beserial Correlation).

Rumus untuk mencari validitas adalah :

$\gamma=\frac{\mathrm{Mp}-\mathrm{Mt}}{\mathrm{St}} \sqrt{ } \frac{\mathrm{P}}{q}$ (Arikunto, 2005: 326)

Dalam penelitian ini reliabilitas diukur dengan menggunakan rumus $\mathrm{K}-$

R.20: $r 11=\frac{\mathrm{K}}{\mathrm{K}-1} \frac{\mathrm{Vt}-\mathrm{pq}}{\mathrm{VT} \text { I }}$

Sebelum dilakukan pengujian analisis data, terlebih dahulu diadakan uji prasyarat analisis yakni dengan pengujian normalitas dan homogenitas antara subjek pada kelompok eksperimen dan kelompok kontrol. Dengan uji normalitas bertujuan untuk mengetahui data penelitian yang telah dikumpulkan berdistribusi normal atau tidak. Uji normalitas menggunakan uji statistik Chi Square. Sedangkan uji homogenitas varian sebagaimana dikemukakan Suharsimi Arikunto (2005: 318) dimaksudkan untuk mengetahui seragam tidaknya varian sampel-sampel yang diambil dari populasi yang sama. Perhitungan uji homogenitas dalam penelitian ini digunakan rumus statistika Levene test dengan bantuan SPSS. Untuk Uji hipotesis ini menggunakan uji-t. Uji-t digunakan untuk mengetahui ada atau tidaknya perbedaan signifikan antara hasil post-test kelompok eksperimen yang diberi treatment penggunaan media video rekam layar pada pembelajaran, dan kelompok kontrol. Hipotesis alternatif atau Ha yang diajukan adalah "terdapat perbedaan signifikan antara subjek yang dalam pembelajarannya menggunakan treatment eksperimen (penggunaan media video rekam layar dibandingkan dengan subjek yang dalam pembelajarannya tidak menggunakan treatment eksperimen. Ho yang diajukan adalah "tidak terdapat perbedaan signifikan antara subjek yang dalam pembelajarannya menggunakan treatment eksperimen dengan subjek yang tidak menggunakan media video rekam layar".

Uji-t dalam penelitian ini dilakukan dua kali. Pertama uji-t untuk data pre-test yang dimaksudkan untuk mengetahui kondisi awal subjek penelitian dari dua kelompok. Kedua, menghitung uji-t untuk data post-test yang dimaksudkan untuh mengetahui pengaruh proses 
belajar mengajar yang dapat dilihat berdasarkan kondisi akhir subjek penelitian setelah diberikan perlakuan. Dalam pengujian hipotesis, peneliti menggunakan bantuan dari program SPSS. Kriteria dalam penerimaan dan penolakan hipotesis adalah :

a.Untuk uji-t, jika diperoleh hasil $t_{\text {hitung }} \geq t_{\text {tabel, }}$ maka hipotesis yang dirumuskan (Ha) diterima $\mathrm{H}$ nol (Ho) ditolak, dan

b.Jika diperoleh $t_{\text {hitung }}<t_{\text {tabel, }}$ maka hipotesis alternatif (Ha) ditolak dan hipotesis nol (Ho) diterima.

\section{HASIL DAN PEMBAHASAN}

\section{Hasil}

\section{Tes Awal (Pre-test)}

Hasil rangkuman pre-test kelas XI TP D ( kelompok eksperimen) dan kelas XI TP C (kelompok kontrol) dapat dilihat pada tabel berikut:

Tabel 1. Hasil Tes Awal (Pre-test) Kelompok Eksperimen dan Kelompok Kontrol

\begin{tabular}{|c|c|c|c|}
\hline No. & Kelas & Jumlah Siswa & Rata-rata \\
\hline 1 & XI TP D (eksperimen) & 34 & 68,71 \\
\hline 2 & XI TP C ( kontrol ) & 35 & 69,37 \\
\hline \multicolumn{2}{|c|}{ Total } & 69 & 140,54 \\
\hline
\end{tabular}

Dari hasil perhitungan statistik, maka diperoleh nilai rata-rata tes awal (pre-test) kelompok eksperimen dan kelompok kontrol adalah 68,71 (enam puluh delapan koma tujuh puluh satu) dan 69,37 (enam puluh sembilan koma tiga puluh tujuh).

Distribusi frekuensi dari hasil pre-test kelompok eksperimen dan kelompok kontrol akan disajikan pada tabel dan gambar berikut ini:

a. Kelompok Eksperimen

Tabel 2. Nilai Awal (Pre-test) Kelompok Eksperimen

\begin{tabular}{|c|c|c|c|}
\hline No & Nilai & Frekuensi (siswa) & Persen (\%) \\
\hline 1 & 32 & 1 & 2,94 \\
\hline 2 & 36 & 1 & 2,94 \\
\hline 3 & 52 & 3 & 8,82 \\
\hline 4 & 56 & 1 & 2,94 \\
\hline 5 & 60 & 5 & 14,71 \\
\hline 6 & 64 & 6 & 17,65 \\
\hline 7 & 68 & 1 & 2,94 \\
\hline 8 & 72 & 1 & 2,94 \\
\hline 9 & 76 & 4 & 11,76 \\
\hline 10 & 80 & 5 & 14,71 \\
\hline 11 & 84 & 4 & 11,76 \\
\hline 12 & 96 & 2 & 5,88 \\
\hline & & 34 & 100 \\
\hline \multicolumn{2}{|c|}{ Jumlah } & & \\
\hline
\end{tabular}

Dari tabel 2 diketahui nilai pre-test kelompok eksperimen untuk nilai terendah adalah 32 (tiga puluh dua), nilai tertinggi 96 (sembilan puluh enam).

b. Kelompok Kontrol

Tabel 4. Nilai Awal (Pre-test) Kelompok Kontrol

\begin{tabular}{|c|c|c|c|}
\hline No & Nilai & Frekuensi (siswa) & Persen (\%) \\
\hline 1 & 44 & 1 & 2,86 \\
\hline
\end{tabular}




\begin{tabular}{|c|c|c|c|}
\hline 2 & 48 & 1 & 2,86 \\
\hline 3 & 52 & 1 & 2,86 \\
\hline 4 & 56 & 4 & 11,43 \\
\hline 5 & 60 & 5 & 14,29 \\
\hline 6 & 64 & 2 & 5,71 \\
\hline 7 & 68 & 3 & 8,57 \\
\hline 8 & 72 & 4 & 11,43 \\
\hline 9 & 76 & 3 & 8,57 \\
\hline 10 & 80 & 6 & 17,14 \\
\hline 11 & 84 & 2 & 5,71 \\
\hline 12 & 88 & 3 & 8,57 \\
\hline & Jumlah & 35 & 100 \\
\hline
\end{tabular}

Dari tabel 4., diketahui nilai pre-test kelompok kontrol untuk nilai terendah adalah 44 (empat puluh empat), nilai tertinggi 88 (delapan puluh delapan).

\section{Pelaksanaan Perlakuan (Treatment)}

Tabel 5. Hasil Observasi Penggunaan Metode Eksperimen terhadap Aktivitas Pendidik Kelompok Eksperimen Pertemuan I dan II

\begin{tabular}{|c|c|c|c|c|c|c|}
\hline \multirow[t]{2}{*}{ No } & \multirow[t]{2}{*}{ Aspek } & \multirow[t]{2}{*}{ Indikator } & \multicolumn{2}{|c|}{ Pertemuan I } & \multicolumn{2}{|c|}{ Pertemuan II } \\
\hline & & & $\mathrm{Ya}$ & Tidak & $\mathrm{Ya}$ & Tidak \\
\hline \multirow[t]{2}{*}{1.} & $\begin{array}{l}\text { Pra } \\
\text { Pembelajaran }\end{array}$ & $\begin{array}{l}\text { 1) Menyiapkan alat } \\
\text { dan bahan } \\
\text { Pembelajaran. }\end{array}$ & $\sqrt{ }$ & & $\sqrt{ }$ & \\
\hline & & $\begin{array}{l}\text { 2) Memeriksa } \\
\text { Kesiapan peserta didik } \\
\text { saat akan mengikuti } \\
\text { PJJ daring dengan } \\
\text { komunikasi di WAG. }\end{array}$ & & $\sqrt{ }$ & $\sqrt{ }$ & \\
\hline \multirow[t]{2}{*}{2.} & $\begin{array}{l}\text { Kegiatan awal } \\
\text { (daring melalui } \\
\text { WAG dan } \\
\text { google }\end{array}$ & $\begin{array}{l}\text { 1) Menyampaikan } \\
\text { Apersepsi dan } \\
\text { memotivasi peserta } \\
\text { didik di WAG. }\end{array}$ & $\sqrt{ }$ & & $\sqrt{ }$ & \\
\hline & classroom) & $\begin{array}{l}\text { 2) Menyampaikan } \\
\text { tujuan dan kegiatan } \\
\text { pembelajaran yang } \\
\text { akan dicapai. }\end{array}$ & $\sqrt{ }$ & & $\sqrt{ }$ & \\
\hline \multirow[t]{5}{*}{3.} & Kegiatan inti & & & & & \\
\hline & $\begin{array}{l}\text { a. Persiapan } \\
\text { eksperimen }\end{array}$ & $\begin{array}{l}\text { 1) Guru membuat } \\
\text { assignment di google } \\
\text { classroom. }\end{array}$ & t) & & $\sqrt{ }$ & \\
\hline & & $\begin{array}{l}\text { 2) Guru menyilakan } \\
\text { peserta didik untuk } \\
\text { masuk google } \\
\text { classroom. }\end{array}$ & $\sqrt{ }$ & & $\sqrt{ }$ & \\
\hline & $\begin{array}{l}\text { b.Pelaksanaan } \\
\text { eksperimen }\end{array}$ & $\begin{array}{l}\text { 1) Membimbing } \\
\text { peserta didik } \\
\text { membuka materi di } \\
\text { google classroom. }\end{array}$ & $\sqrt{4}$ & & $\sqrt{ }$ & \\
\hline & & $\begin{array}{l}\text { 2) Menguasai } \\
\text { penggunaan alat }\end{array}$ & & $\sqrt{ }$ & $\sqrt{ }$ & \\
\hline
\end{tabular}




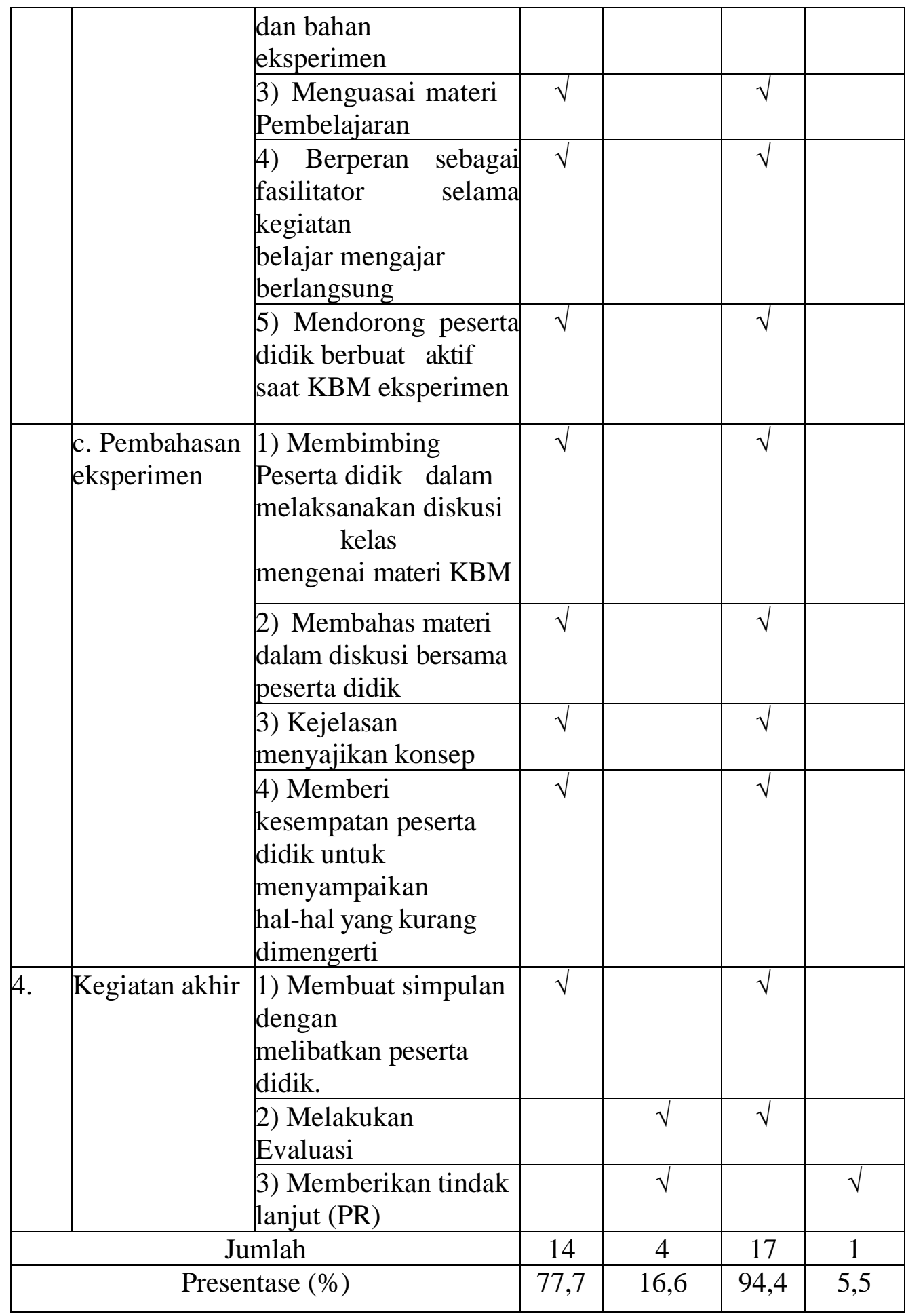

Berdasarkan tabel 5, dapat disimpulkan bahwa hasil observasi aktivitas pendidik kelompok eksperimen dengan menggunakan media video rekam layar diketahui pertemuan I didapatkan hasil aspek pra pembelajaran sebesar 1 dan pertemuan II sebesar 2. Pada aspek kegiatan awal pada pertemuan I dan pertemuan II sebesar 2. Pada aspek kegiatan inti pada pertemuan I sebesar 10 dan pertemuan II sebesar 11. Pada aspek kegiatan akhir sebesar 1 dan pertemuan II sebesar 2 dengan persentase pada pertemuan I sebesar 77,7\% dan pertemuan II sebesar 94,4\%.Ini berarti aktivitas pendidik mengalami peningkatan sebesar 16,7\%.

1) Hasil Observasi Aktivitas Peserta Didik Kelompok Eksperimen Pertemuan I dan II

Hasil observasi aktivitas peserta didik kelompok eksperimen pada pertemuan I dan II disajikan pada tabel dan gambar berikut: 
EDUTECH : Jurnal Inovasi Pendidikan Berbantuan Teknologi Vol. 1 No. 3 November 2021, e-ISSN : 2797-0140 | p-ISSN : 2797-0590

Tabel 6. Hasil Observasi Penggunaan Metode Eksperimen terhadap Aktivitas Peserta Didik Kelompok Eksperimen Pertemuan I dan II

\begin{tabular}{|c|c|c|c|c|}
\hline \multirow[t]{2}{*}{ No } & \multirow[t]{2}{*}{ Aspek } & \multirow[t]{2}{*}{ Indikator } & Pertemuan I & Pertemuan II \\
\hline & & & Frekuensi & Frekuensi \\
\hline \multirow[t]{5}{*}{1.} & \multirow[t]{5}{*}{ Keaktifan } & $\begin{array}{l}\text { a. Menanyakan hal- } \\
\text { hal yang kurang dimengerti }\end{array}$ & 10 & 12 \\
\hline & & $\begin{array}{l}\text { b. Menyatakan pendapat/ } \\
\text { gagasannya }\end{array}$ & 11 & 12 \\
\hline & & $\begin{array}{l}\text { c. Menjawab pertanyaan } \\
\text { guru/teman }\end{array}$ & 25 & 27 \\
\hline & & $\begin{array}{l}\text { d. Keterlibatan dalam } \\
\text { bereksperimen }\end{array}$ & 30 & 34 \\
\hline & & $\begin{array}{l}\text { e. Keterlibatan } \\
\text { dalam diskusi } \\
\text { kelompok } \\
\text { maupun diskusi kelas } \\
\text { (daring) }\end{array}$ & 30 & 34 \\
\hline \multirow[t]{2}{*}{2.} & \multirow[t]{2}{*}{ Kesenangan } & $\begin{array}{l}\text { a. Senang dan } \\
\text { tertarik untuk } \\
\text { terlibat eksperimen }\end{array}$ & 29 & 34 \\
\hline & & \begin{tabular}{|l|} 
b. Antusias dalam \\
melaksanakan \\
dari guru
\end{tabular} & 32 & 34 \\
\hline \multirow[t]{2}{*}{3.} & \multirow[t]{2}{*}{ Kreativitas } & $\begin{array}{l}\text { a. Keterampilan } \\
\text { menyiapkan respons saat } \\
\text { diskusi }\end{array}$ & 15 & 24 \\
\hline & & $\begin{array}{l}\text { b. Keterampilan } \\
\text { menyajikan bahan materi }\end{array}$ & 20 & 25 \\
\hline \multirow[t]{3}{*}{4.} & \multirow[t]{3}{*}{$\begin{array}{l}\text { Kemampuan } \\
\text { berpikir }\end{array}$} & $\begin{array}{l}\text { a. Mengajukan pertanyaan } \\
\text { yang } \\
\text { relevan }\end{array}$ & 11 & 14 \\
\hline & & $\begin{array}{l}\text { b. Menjawab pertanyaan } \\
\text { dengan tepat }\end{array}$ & 10 & 15 \\
\hline & & $\begin{array}{l}\text { c. Menyelesaikan KBM } \\
\text { sesuai waktu }\end{array}$ & 29 & 32 \\
\hline & & Jumlah & 262 & 297 \\
\hline \multicolumn{3}{|c|}{ Persentase (\%) } & 64,21 & 72,79 \\
\hline
\end{tabular}

Berdasarkan tabel 6 dapat disimpulkan bahwa hasil observasi aktivitas peserta didik kelompok eksperimen dengan menggunakan metode eksperimen, diketahui pertemuan I didapatkan hasil aspek keaktifan pada pertemuan I sebesar 106 dan pertemuan II sebesar 117. Pada aspek kesenangan pada pertemuan I sebesar 61 dan pertemuan II sebesar 68. Pada aspek kreativitas pertemuan I 35 dan pertemuan II sebesar 49. Pada aspek kemampuan berpikir pada pertemuan I sebesar 50 dan pertemuan II sebesar 61 dengan persentase pada pertemuan I sebesar $64,21 \%$ dan pertemuan II sebesar $72,79 \%$. Ini berarti aktivitas peserta didik mengalami peningkatan sebesar $8,58 \%$.

a. Data hasil observasi kelompok Kontrol dengan menggunakan metode Konvensional 
EDUTECH : Jurnal Inovasi Pendidikan Berbantuan Teknologi Vol. 1 No. 3 November 2021, e-ISSN : 2797-0140 | p-ISSN : 2797-0590

Tabel 7. Hasil Observasi Penggunaan Media Konvensional terhadap Aktivitas Pendidik Kelompok Kontrol Pertemuan I dan II

\begin{tabular}{|c|c|c|c|c|c|c|}
\hline \multirow[t]{2}{*}{$\mathrm{No}$} & \multirow[t]{2}{*}{ Aspek } & \multirow[t]{2}{*}{ Indikator } & \multicolumn{2}{|c|}{ Pertemuan I } & \multicolumn{2}{|c|}{ Pertemuan II } \\
\hline & & & $\mathrm{Ya}$ & Tidak & $\mathrm{Ya}$ & Tidak \\
\hline \multirow[t]{2}{*}{1.} & Pra pembelajaran & $\begin{array}{l}\text { 1) Menyiapkan alat } \\
\text { dan bahan } \\
\text { pembelajaran }\end{array}$ & & $\sqrt{ }$ & & $\sqrt{ }$ \\
\hline & & $\begin{array}{l}\text { 2) Memeriksa kesiapan } \\
\text { peserta didik melalui WAG }\end{array}$ & $\sqrt{ }$ & & $\sqrt{ }$ & \\
\hline \multirow[t]{2}{*}{2.} & Kegiatan awal & $\begin{array}{l}\text { 1) Menyampaikan } \\
\text { apersepsi dan } \\
\text { memotivasi peserta didik } \\
\text { melalui WAG }\end{array}$ & $\sqrt{ }$ & & $\sqrt{ }$ & \\
\hline & & $\begin{array}{l}\text { 2) Menyampaikan tujuan } \\
\text { dan kegiatan pembelajaran } \\
\text { yang } \\
\text { akan dicapai }\end{array}$ & $\sqrt{ }$ & & $\sqrt{ }$ & \\
\hline \multirow[t]{10}{*}{3.} & Kegiatan inti & & & & & \\
\hline & a. Persiapan & $\begin{array}{l}\text { 1) Membagi peserta didik } \\
\text { menjadi beberapa } \\
\text { kelompok heterogen dalam } \\
\text { WAG }\end{array}$ & & $\sqrt{ }$ & & $\sqrt{ }$ \\
\hline & & $\begin{array}{l}\text { 2) Memeriksa kelengkapan } \\
\text { alat dan bahan } \\
\text { pembelajaran }\end{array}$ & & $\sqrt{ }$ & & $\sqrt{ }$ \\
\hline & b. Pelaksanaan & $\begin{array}{l}\text { 1) Membimbing peserta } \\
\text { didik melaksanakan } \\
\text { pembelajaran sesuai } \\
\text { langkah-langkah }\end{array}$ & & $\sqrt{ }$ & & $\sqrt{ }$ \\
\hline & & $\begin{array}{l}\text { 2) Menguasai penggunaan } \\
\text { alat dan } \\
\text { bahan dalam KBM }\end{array}$ & & $\sqrt{ }$ & & $\sqrt{ }$ \\
\hline & & $\begin{array}{l}\text { 3) Menguasai materi } \\
\text { Pembelajaran }\end{array}$ & $\sqrt{ }$ & & $\sqrt{ }$ & \\
\hline & & $\begin{array}{l}\text { 4) Berperan } \\
\text { fasilitator selama kegai } \\
\text { belajar mengajar } \\
\text { berlangsung }\end{array}$ & & $\sqrt{ }$ & & $\sqrt{ }$ \\
\hline & & $\begin{array}{l}\text { 5) Mendorong peserta didik } \\
\text { berbuat aktif }\end{array}$ & & $\sqrt{ }$ & & $\sqrt{ }$ \\
\hline & \multirow[t]{2}{*}{ c. Pembahasan } & $\begin{array}{l}\text { 1) Membimbing peserta } \\
\text { didik dalam melaksanakan } \\
\text { diskusi kelas } \\
\text { mengenai hasil } \\
\text { kegiatan pembelajaran }\end{array}$ & & $\sqrt{ }$ & & $\sqrt{ }$ \\
\hline & & $\begin{array}{l}\text { 2) Membahas materi } \\
\text { melalui diskusi bersama } \\
\text { peserta didik. }\end{array}$ & & $\sqrt{ }$ & & $\sqrt{ }$ \\
\hline
\end{tabular}




\begin{tabular}{|c|c|c|c|c|c|c|}
\hline & & $\begin{array}{l}\text { 3) Kejelasan } \\
\text { menyajikan konsep }\end{array}$ & & $\sqrt{ }$ & & $\sqrt{ }$ \\
\hline & & $\begin{array}{l}\text { 4) Memberi kesempatan } \\
\text { peserta didik untuk } \\
\text { menyampaikan hal- hal } \\
\text { yang kurang dimengerti }\end{array}$ & & $\sqrt{ }$ & $\sqrt{ }$ & \\
\hline 4. & Kegiatan akhir & $\begin{array}{l}\text { 1) Membuat kesimpulan } \\
\text { dengan } \\
\text { melibatkan peserta didik }\end{array}$ & $\sqrt{ }$ & & $\sqrt{ }$ & \\
\hline & & 2) Melakukan evaluasi & & $\sqrt{ }$ & $\sqrt{ }$ & \\
\hline & & $\begin{array}{l}\text { 3) Memberikan tindak } \\
\text { lanjut (PR) }\end{array}$ & & $\sqrt{ }$ & & $\sqrt{ }$ \\
\hline & & Jumlah & 5 & 13 & 7 & 11 \\
\hline & & sentase $(\%)$ & 27,7 & 72,2 & 38,8 & 61,1 \\
\hline
\end{tabular}

Berdasarkan tabel 7, terlihat bahwa pendidik pada kelompok kontrol dengan menggunakan metode konvesional pada aspek kegiatan akhir pada pertemuan I sebesar 1 sedangkan pada pertemuan II sebesar 2 dengan presentase pada pertemuan I sebesar $27,7 \%$ dan pada pertemuan II sebesar $38,8 \%$. Ini berarti aktivitas pendidik mengalami peningkatan sebesar $11,1 \%$.

3) Hasil Observasi Kelompok Kontrol Aktivitas Peserta Didik Pertemuan I dan II Hasil observasi aktivitas peserta didik kelompok kontrol pada pertemuan I dan II disajikan pada tabel dan gambar berikut ini:

Tabel 8. Hasil Observasi Penggunaan Metode Konvensional terhadap Aktivitas Peserta Didik Kelompok Kontrol Pertemuan I dan II

\begin{tabular}{|c|c|c|c|c|}
\hline \multirow[t]{2}{*}{ No } & \multirow[t]{2}{*}{ Aspek } & \multirow[t]{2}{*}{ Indikator } & Pertemuan I & Pertemuan II \\
\hline & & & Frekuensi & Frekuensi \\
\hline \multirow[t]{5}{*}{1.} & \multirow[t]{5}{*}{ Keaktifan } & $\begin{array}{l}\text { a. Menanyakan } \\
\quad \text { hal- } \\
\text { hal yang kurang } \\
\text { dimengerti }\end{array}$ & 8 & 10 \\
\hline & & $\begin{array}{l}\text { b. Menyatakan } \\
\text { pendapat/ } \\
\text { gagasannya }\end{array}$ & 5 & 8 \\
\hline & & $\begin{array}{l}\text { c. Menjawab } \\
\text { pertanyaan guru/teman }\end{array}$ & 34 & 34 \\
\hline & & $\begin{array}{l}\text { d. Keterlibatan dalam } \\
\text { kegiatan belajar } \\
\text { mengajar }\end{array}$ & 0 & 0 \\
\hline & & $\begin{array}{l}\text { e. Keterlibatan dalam } \\
\text { diskusi kelompok } \\
\text { maupun diskusi kelas }\end{array}$ & 0 & 0 \\
\hline 2. & Kesenangan & $\begin{array}{l}\text { a. Senang dan tertarik } \\
\text { untuk terlibat dalam } \\
\text { KBM }\end{array}$ & 0 & 0 \\
\hline
\end{tabular}




\begin{tabular}{|c|c|c|c|c|}
\hline & & $\begin{array}{l}\text { b. Antusias dalam } \\
\text { melaksanakan } \\
\text { tugas dari pendidik }\end{array}$ & 0 & 0 \\
\hline \multirow[t]{2}{*}{3 . } & \multirow[t]{2}{*}{ Kreativitas } & $\begin{array}{l}\text { a. Keterampilan } \\
\text { menyiapkan respons }\end{array}$ & 0 & 0 \\
\hline & & $\begin{array}{l}\text { b. Keterampilan } \\
\text { menyampaikan respons }\end{array}$ & 0 & 0 \\
\hline \multirow[t]{3}{*}{4} & \multirow[t]{3}{*}{$\begin{array}{l}\text { Kemampuan } \\
\text { berpikir }\end{array}$} & $\begin{array}{l}\text { a. Mengajukan } \\
\text { pertanyaan yang } \\
\text { relevan }\end{array}$ & 7 & 10 \\
\hline & & $\begin{array}{l}\text { b. Menjawab } \\
\text { pertanyaan dengan } \\
\text { tepat }\end{array}$ & 5 & 10 \\
\hline & & $\begin{array}{l}\text { c. Menyelesaikan } \\
\text { KBM sesuai aokasi } \\
\text { waktu. }\end{array}$ & 0 & 0 \\
\hline & \multirow{2}{*}{\multicolumn{2}{|c|}{ Jumlah }} & 54 & 68 \\
\hline \multicolumn{2}{|c|}{ Persentase (\%) } & & 15,51 & 19,54 \\
\hline
\end{tabular}

Berdasarkan tabel 8, dapat disimpulkan bahwa hasil observasi aktivitas peserta didik kelompok eksperimen dengan menggunakan metode eksperimen, diketahui pertemuan I didapatkan hasil aspek keaktifan pada pertemuan I sebesar 47 dan pertemuan II sebesar 52. Pada aspek kesenangan dan kreativitas pertemuan I dan II sebesar 0. Pada aspek kemampuan berpikir pada pertemuan I sebesar 12 dan pertemuan II sebesar 20 dengan persentase pada pertemuan I sebesar 15,51\% dan pertemuan II sebesar 19,54\%. Ini berarti aktivitas peserta didik mengalami peningkatan sebesar $4,03 \%$.

\section{Tes Akhir (post-test)}

Berikut ini adalah rangkuman hasil post-test kelompok eksperimen dan kelompok kontrol.

Tabel 9. Hasil Tes Akhir (Post-test) Kelompok Eksperimen dan Kelompok Kontrol.

\begin{tabular}{|c|c|c|c|}
\hline No & \multicolumn{1}{|c|}{ Kelas } & $\begin{array}{l}\text { Jumlah } \\
\text { Peserta Didik }\end{array}$ & Rata-rata \\
\hline 1 & XI TP D (eksperimen) & 34 & 79,08 \\
\hline 2 & XI TP C ( kontrol ) & 35 & 71,86 \\
\hline \multicolumn{2}{|c|}{ Total } & 69 & 150,94 \\
\hline
\end{tabular}

Dari tabel 9, diketahui nilai rata-rata kelompok eksperimen dan kelompok kontrol adalah 79,08 (tujuh puluh sembilan koma nol delapan) dan 71,86 (tujuh puluh satu koma delapan enam).

Berdasarkan tabel 9, terlihat perbedaan rata- rata nilai yang dicapai oleh kelompok eksperimen dan kelompok kontrol. Hasil tes pada kelompok eksperimen mengalami peningkatan sebesar 10,37, yakni dari tes awal 68,71 mengalami peningkatan menjadi 79,08. Sedangkan pada kelompok kontrol juga mengalami peningkatan, yakni dari tes awal 69,37 menjadi 71,86 hanya mengalami peningkatan sebesar 2,49 peningkatan hasil tes kelompok kontrol tidak sebesar pada kelompok eksperimen. Distribusi frekuensi dari hasil post-test kelompok eksperimen dan kelompok kontrol akan disajikan dalam tabel berikut ini:

a. Kelompok Eksperimen

Tabel 10. Nilai Akhir (Post-test) Kelompok Eksperimen 


\begin{tabular}{|c|c|c|c|}
\hline No & Nilai & $\begin{array}{c}\text { Frekuensi } \\
\text { (peserta didik) }\end{array}$ & Persen (\%) \\
\hline 1 & 56 & 2 & 5,88 \\
\hline 2 & 60 & 2 & 5,88 \\
\hline 3 & 64 & 2 & 5,88 \\
\hline 4 & 68 & 4 & 11,76 \\
\hline 5 & 72 & 4 & 11,76 \\
\hline 6 & 76 & 5 & 14,70 \\
\hline 7 & 84 & 3 & 8,8 \\
\hline 8 & 88 & 3 & 8,8 \\
\hline 9 & 92 & 7 & 20,59 \\
\hline 10 & 96 & 2 & 5,88 \\
\hline Jumlah & & 34 & 100 \\
\hline
\end{tabular}

Dari tabel 10, diketahui nilai post-test kelompok eksperimen untuk nilai terendah adalah 56 (lima puluh enam), nilai tertinggi 96 (sembilan puluh enam).

b. Kelompok Kontrol

Tabel 11. Nilai Akhir (Post-test) Kelompok Kontrol

\begin{tabular}{|c|c|c|c|}
\hline No & Nilai & $\begin{array}{c}\text { Frekuensi (peserta } \\
\text { didik) }\end{array}$ & Persen $(\%)$ \\
\hline 1 & 44 & 1 & 2,85 \\
\hline 2 & 48 & 2 & 5,71 \\
\hline 3 & 52 & 1 & 2,85 \\
\hline 4 & 60 & 1 & 2,85 \\
\hline 5 & 64 & 7 & 20 \\
\hline 6 & 68 & 5 & 14,28 \\
\hline 7 & 72 & 2 & 5,71 \\
\hline 8 & 76 & 3 & 8,57 \\
\hline 9 & 80 & 3 & 8,57 \\
\hline 10 & 84 & 5 & 14,28 \\
\hline 11 & 88 & 3 & 8,57 \\
\hline 12 & 96 & 1 & 2,85 \\
\hline \multicolumn{2}{|c|}{ Jumlah } & 35 & 100 \\
\hline
\end{tabular}

Dari tabel 11, diketahui nilai post-test kelompok kontrol untuk nilai terendah adalah 44 (empat puluh empat), nilai tertinggi 96 (sembilan puluh enam).

\section{B. Uji Analisis Data}

1. Uji Normalitas

Tabel 12. Hasil Uji Normalitas Kelompok Eksperimen dan Kontrol

\begin{tabular}{|l|l|c|c|c|}
\hline \multicolumn{2}{|c|}{ Variabel } & $\begin{array}{l}\text { Chi- } \\
\text { Square }\end{array}$ & Asymp.Sig. & Keterangan \\
\hline \multirow{2}{*}{ Eksperimen } & Pre-test & 16,103 & 0,137 & Normal \\
\cline { 2 - 5 } & Post-test & 11,345 & 0,253 & Normal \\
\hline \multirow{2}{*}{ Kontrol } & Pre-test & 11,138 & 0,432 & Normal \\
\cline { 2 - 5 } & Post-test & 7,828 & 0,729 & Normal \\
\hline
\end{tabular}

Berdasarkan tabel 12, dapat diketahui bahwa pre-test kelompok eksperimen mempunyai taraf signifikansi sebesar 0,137 atau lebih dari 0,05, maka dapat dinyatakan bahwa data tesebut 
berdistribusi normal. Untuk sebaran post-test kelompok eksperimen mempunyai nilai signifikansi 0,253 atau lebih dari 0,05, maka data post-test dapat dikatakan berdistribusi normal. Untuk data pre-test kelompok kontrol mempunyai nilai signifikansi sebesar 0,432 atau lebih dari 0,05 , maka dapat dikatakan data tersebut berdistribusi normal. Sebaran data post-test kelompok kontrol mempunyai nilai signifikansi sebesar 0,729 atau lebih besar dari 0,05, maka dapat dikatakan data tersebut berdistribusi normal. Dari hasil uji normalitas tersebut dapat disimpulkan bahwa data yang diperoleh berdistribusi normal.

\section{Uji Homogenitas}

Tabel 13. Hasil Uji Homogenitas Kelompok Eksperimen dan Kontrol

\begin{tabular}{|l|c|c|c|}
\hline Variabel & Levene Statistic & Sig & Keterangan \\
\hline $\begin{array}{l}\text { Pre-test kelompok } \\
\text { eksperimen- kontrol }\end{array}$ & 1,329 & 0,254 & Homogen \\
\hline $\begin{array}{l}\text { Post-test kelompok } \\
\text { eksperimen- kontrol }\end{array}$ & 0,052 & 0,821 & Homogen \\
\hline
\end{tabular}

Berdasarkan tabel 13, dapat diketahui bahwa untuk uji homogenitas pada pre-test kelompok eksperimen dan kelompok kontrol diperoleh nilai signifikansi sebesar 0,254, nilai signifikansi post-test kelompok eksperimen dan kelompok kontrol sebesar 0,821. Dari penjelasan tersebut, maka dapat diketahui bahwa semua nilai signifikansi lebih besar dari 0,05 . Jadi dapat disimpulkan bahwa populasi memiliki varian yang homogen atau data berasal dari populasi dengan varian yang sama.

3. Uji t

a. Uji t Pre-test kelompok Eksperimen dan Kelompok Kontrol

Tabel 14. Hasil Uji t Pre-test kelompok Eksperimen dan kelompok Kontrol

\begin{tabular}{|l|c|l|l|l|}
\hline Variabel & Mean & thitung & Sig & Keterangan \\
\hline Kelompok Eksperimen & 68,96 & 3,470 & 0,463 & Tidak Ada Beda \\
\hline Kelompok Kontrol & 71,58 & & & \\
\hline
\end{tabular}

Berdasarkan tabel di atas, hasil analisis untuk uji t menunjukkan bahwa nilai t sebesar 3,470 dan nilai signifikansi 0,463. Nilai signifikansi menyatakan lebih besar dari 0,05 , maka dapat dinyatakan bahwa Ha ditolak dan Ho diterima, yang artinya tidak ada perbedaan yang signifikan hasil pre-test kelompok eksperimen dan kelompok kontrol. Jadi dapat disimpulkan bahwa antara kelompok eksperimen dan kelompok kontrol memiliki kemampuan sama.

\section{b. Uji t Post-test Kelompok Eksperimen dan Kelompok Kontrol}

Tabel 15. Hasil Uji t Post-test Kelompok Eksperimen dan Kelompok Kontrol

\begin{tabular}{|l|l|l|l|l|}
\hline \multicolumn{1}{|c|}{ Variabel } & Mean & t hitung & Sig & Keterangan \\
\hline Kelompok Eksperimen & 79,03 & 0,115 & 0,036 & Ada \\
Kelompok Kontrol & 71,86 & & & Perbedaan \\
\hline
\end{tabular}

Berdasarkan tabel di atas, hasil analisis uji t menunjukkan bahwa nilai t sebesar 0,115 dan nilai signifikansi 0,036. Nilai signifikansi menyatakan lebih kecil 0,05, maka dapat dinyatakan bahwa Ha diterima dan Ho ditolak, yang artinya ada perbedaan yang signifikan hasil post-test kelompok eksperimen dengan kelompok kontrol. Dengan demikian, dapat disimpulkan bahwa ada perbedaan yang signifikan hasil post-test kelompok eksperimen yang pembelajarannya menggunakan media video rekam layar dengan kelompok kontrol yang pembelajarannya menggunakan metode konvensional yaitu metode daring bermedia pembelajaran tertulis searah.

\section{Pembahasan}

Hasil analisis uji t menunjukkan bahwa nilai t sebesar 0,115 dan nilai signifikansi 0,036. Nilai signifikansi menyatakan lebih kecil 0,05, maka dapat dinyatakan bahwa Ha diterima dan Ho ditolak, yang artinya ada perbedaan yang signifikan hasil post-test kelompok eksperimen dengan kelompok kontrol. Dengan demikian, dapat disimpulkan bahwa ada perbedaan yang 
signifikan hasil post-test kelompok eksperimen yang pembelajarannya menggunakan media video rekam layar pada pembelajaran proposal, dengan kelompok kontrol yang pembelajarannya menggunakan metode konvensional yaitu metode daring bermedia pembelajaran tertulis searah atau pun ceramah. Hal ini sesuai dengan hasil penelitian yang menyimpulkan bahwa melalui penggunaan aplikasi rekam layar meningkatkan kemampuan pengetahuan fisika kelas XII-MIPA.3 peserta didik SMA Negeri 2 Bangkalan 2020/2021 (Muhammad Saeri, 2020).

Begitu juga dengan hasil Penelitian "Discovery Learning Menggunakan Video Rekam Layar pada Pembelajaran Matematika" menyimpulkan bahwa terdapat pengaruh positif dalam keaktifan dan kemampuan peserta didik SMA Negeri 1 Ulujami, Pemalang setelah menggunakan video rekam layar pada model pembelajaran discovery learning (Sutono, 2020).

Berbagai hasil penelitian menunjukkan bahwa orang lebih tertarik belajar menggunakan media video daripada belajar melalui media teks dan gambar diam (Fadhli, 2015: 11). Dari pendapat tersebut tertulis jelas bahwa ketertarikan peserta didik semakin bertambah saat media pembelajaran berupa video. Pembelajaran bermedia video dianggap efektif membuat peserta didik lebih dapat menerima pembelajaran yang diberikan kepadanya (Putri, 2012:24). Banyak pihak dalam dunia pendidikan memilih menggunakan video sebagai media pembelajaran.

\section{KESIMPULAN}

Berdasarkan hasil penelitian dan pembahasan, dapat disimpulkan bahwa penggunaan media video rekam layar dalam pembelajaran memberikan pengaruh positif terhadap prestasi belajar bahasa Indonesia materi proposal. Hal tersebut dapat ditunjukkan dengan hasil uji hipotesis data yang diperoleh. Berdasarkan hasil analisis data menunjukkan bahwa hasil prestasi belajar bahasa Indonesia materi proposal pada kelompok eksperimen dan kelompok kontrol diperoleh nilai rerata sebesar 79,03 dengan nilai tertinggi 96 dan nilai terendah 56, sedangkan kelompok kontrol dengan menggunakan metode konvensional memiliki nilai rerata sebesar 71,86 dengan nilai tertinggi 96 dan nilai terendah 44.

Dilihat dari rata-rata nilai pre-test dan post-test untuk hasil belajar kognitif bahasa Indonesia materi proposal pada kedua kelompok di atas, maka dapat diketahui bahwa peningkatan rata-rata untuk hasil belajar pada kelompok eksperimen lebih besar dibandingkan dengan yang terjadi pada kelompok kontrol. Peningkatan nilai rerata hasil belajar peserta didik pada materi proposal dengan menggunakan metode eksperimen menunjukkan bahwa peserta didik dapat lebih memahami materi proposal yang dipelajari lebih bermakna.

Selain itu berdasarkan hasil pengujian hipotesis kedua, hasil post-test kelompok eksperimen dan kelompok kontrol diperoleh t hitung sebesar 0,115 dan nilai signifikansi sebesar 0,036. Nilai signifikansi menyatakan lebih kecil 0,05, maka dapat dikatakan bahwa ada perbedaan yang signifikan antara hasil post-test kelompok eksperimen dan kelompok kontrol. Berdasarkan analisis data dapat dikatakan bahwa prestasi belajar bahasa Indonesia dipengaruhi oleh penggunaan metode eksperimen pada kegiatan pembelajaran.

Berdasarkan kesimpulan hasil penelitian di atas, maka peneliti mengajukan saran bagi guru mata pelajaran hendaknya dapat lebih variatif dalam menyajikan pembelajaran, media video rekam layar dapat dimodifikasi dengan disampaikan melalui media yang familiar dengan peserta didik. Peserta didik diharapkan dapat lebih aktif karena penyampaian materi pembelajaran dimodifikasi sedemikian rupa agar membawa hasil belajar maksimal.

\section{DAFTAR PUSTAKA}

Arikunto, Suharsimi. (2005). Prosedur Penelitian Suatu Pendekatan Praktik. Jakarta: PT Rineka Cipta

Budiningsih, Asri. (2005). Belajar dan Pembelajaran. Jakarta: PT Rineka Cipta. 
Fadli. (2015). Analisis Faktor-Faktor Yang Mempengaruhi Keputusan Mahasiswa Dalam Memilih Jurusan Akutansi Sebagai Tempat Kuliah Di Universitas Di Kota Pekanbaru. Jurnal JOM. FEKON, Vol.2. No.2

Putri, N. (2012). Efektifitas Penggunaan Media Video untuk Meningkatkan Pengenalan Alat Musik Daerah Pada Pembelajaran IPS Bagi Anak Tunagrahita Ringan Di SDLB 20 Kota Solok. Jurnal Ilmiah Pendidikan Khusus, 1(2), 318-328.

Saeri, Muhammad. (2020). Pembelajaran Fisika dengan Video Rekam Layar pada Masa Pandemi Covid-19 untuk mengoptimalkan Kemampuan Belajar Siswa Kelas XIIMIPA.1 Pokok Bahasan Listrik Dinamis SMA Negeri Bangkalan. Jurnal Kependidikan, Pembelajaran, dan Pengembangan. Vol 02, No. 02

Slavin, R.E. (2000). Educational Psychology: Theory and Practice Sixth Edition. Boston: Allyn and Bacon.

Sutono. Discovery Learning Menggunakan Video Rekam Layar pada Pembelajaran Matematika diambil dari radarsemarang.jawapos.com pada 15 November 2021 pukul 20.57 WIB. 